composition of the parasitic fauna is determined also by the nature of the food and digestive equipment of the host, and other influential factors are age, general condition as indicated by states of nutrition or inanition, times of spawning, migration, hibernation and even speeds of locomotion. The nature of the integument of the host and its secretions influence parasites which penetrate the skin, some of which are parasites of man. Many patterns of correlated environmental factors fluctuate periodically and modify the composition of the parasitic fauna.

Dogiel's influence is seen in various chapters of the book dealing with such topics as the ecology of parasites of marine and freshwater fishes, questions concerning host-parasite relationships, specificity, life-cycles and zoogeography. Some consideration is given to the parasites of fishes living in reservoirs, changes in the parasitic fauna of acclimatized fishes, parasitic diseases of fishes living in natural waters and also cultured fishes, and fishes as transmitters of human helminthic disease. The parasites considered are mainly Protozoa, Platyhelminthes, Nematoda, Acanthocephala and Copepoda. Many isolated observations provide interesting revelations but extensive regional surveys may give the specialist more satisfaction. The format is pleasing, the translation is readable, and the text is illustrated with diagrams and maps and supplemented by comprehensive tables. More than 700 references to the original literature are cited, nearly two-thirds of them from the Russian. Errors are few and mainly typographical but sometimes surprising: the statement on p. 105, "Monogenoideans with a single host", refers to several digenetic trematodes but no monogenetic forms.

Students and teachers will find in the book a fund of readily assimilable information, and if the appetite of the specialist is sometimes unsatisfied the gaps more often than not indicate the opportunities for research workers in the future. All concerned with the production of the book deserve credit for giving biologists this opportunity to evaluate Russian progress in a branch of parasitology which has been neglected in Britain. BEN DAwES

\section{SALT MARSHES AND SALT DESERTS}

Salt Marshes and Salt Deserts of the World

By Prof. V. J. Chapman. (Plant Science Monographs.) Pp. xvi $+392+45$ plates. (London: Leonard Hill (Books), Ltd.; New York: Interscience Publishers, Inc., 1960.) 95s. net.

L

ET the good things be placed on record first. This book brings together a wealth of informs. tion from widely scattered and often inaccessible sources and illuminates it with the author's own long experience of salt marshes. Any student undertaking work in this field in the future will certainly start by "looking it up in Chapman". For this service all botanists will be grateful; but gratitude need not blind us to the book's many faults, nor will it arm the struggling reader against exasperation. For the book is, frankly, not so much written as thrown together.

It opens inauspiciously with a chapter which hovers uneasily between a statement of intentions and a summary of findings. This is followed by three chapters on general features of the habitat, the chief fault of which is that they are insufficiently general; all too often a promising principle collapses into a detailed study of a specific example. In the next five chapters we are taken on a conducted tour of the salt marshes of the world, and here the author is at his best; we realize that information about the different areas will be uneven, and presentation of these scattered and largely unrelated data is congenial to the author's discursive style. Elaborate and detailed successional schemes are, however, given with an off-hand confidence which is likely to arouse misgivings. Finally, there are three miscellaneous chapters. The first of these summarizes the author's own views on the successions and phytosociological entities represented, and these are most welcome; but the chapter continues with a quantitative study of the affinities between communities which suggests that the author is unaware of the difficulties in devising and interpreting parameters suitable for this type of comparison. The chapter ends, unaccountably, with a brief account of salt-marsh fucoids. Then follows a disastrous chapter on "Physiology of Halophytes", in which the whole of the thinking concerning transpiration is out of date, and the statements concerning ion uptake simply fail to make sense. The book ends with a brief but interesting account of economic uses.

It is all clearly the work of a man passionately devoted to his subject, avidly and uneritieally welcoming any scrap of information which comes his way, but still too involved in minutiæ to discern underlying patterns. If Prof. Chapman, secure in his remarkable knowledge, had brooded over his information for a year or two, and then written, and re-written, and revised, he might have given us a new classic; as it is, botanists can only weep for what might have been and go and buy the book.

W. T. WILLIAMS

\section{MICROSCOPY IN A MAZE}

The Encyclopedia of Microscopy

Edited by Prof. George L. Clark. Pp. xiii +693 . (Now York: Reinhold Publishing Corporation; London: Chapman and Hall, Ltd., 1961.) 200s. net.

HIS is not an encyclopædia in the ordinary sense, but a collection of 140 articles. There is no index, and the subject titles are not always helpful. It is thus very difficult to look up any specific point. The articles are strung together with little correlation or cross-reference, leading to useless repetition or omission of important topics. The two articles on interference microscopy cover much common ground and contain several similar diagrams, but no adequate discussion of phase contrast is to be found. There is a good article on the design of the polarizing microscope for detecting very weak birefringence, but no proper deseription of the basic instrument or its use in crystallography. Fluorescence microscopy is represented by two pages from a commercial brochure. Fluorescence labelling of proteins, which has led to one of the most important advances in modern biological microscopy, is not mentioned.

The section on ultra-violet microscopy contains three pages on methods, with almost no discussion of results or applications, one page on colour translating television systems (with no references) and more than nine pages on "Image Formation by a Fresnel Zone Plate". The latter article might find a place as an original paper in a specialist journal; but why 